\title{
INFLUENCE OF ENERGY DENSITY OF DIFFERENT LIGHT SOURCES ON KNOOP HARDNESS OF A DUAL-CURED RESIN CEMENT
}

\author{
Evandro PIVA ${ }^{1}$, Lourenço CORRER-SOBRINHO ${ }^{2}$, Mario Alexandre Coelho SINHORETI ${ }^{2}$, Simonides CONSANI ${ }^{2}$, \\ Flávio Fernando DEMARCO², John Michael POWERS ${ }^{3}$
}

1-DDS, MSc, PhD, Professor, Department of Restorative Dentistry, Dental School, Federal University of Pelotas, Pelotas, RS, Brazil.

2-DDS, PhD, Professor, Department of Restorative Dentistry, Dental Materials Area, Dental School of Piracicaba, State University of Campinas, SP, Brazil.

3- PhD, Restorative Dentistry and Biomaterials, University of Texas Dental Branch at Houston, Houston, TX, USA.

Corresponding address: Prof. Evandro Piva - Centro de Desenvolvimento e Controle de Biomateriais, FO/UFPel - Rua Gonçalves Chaves, 457/504, Centro, 96015-560 Pelotas, RS, Brasil. - Phone/Fax 555332226690 ramal 135 - e-mail: piva@ufpel.edu.br

Received: August 20, 2007 - Modification: November 27, 2007 - Accepted: February 28, 2008

\begin{abstract}
$\Gamma^{\prime}$

he purpose of this study was to evaluate the Knoop hardness of a dual-cured resin-based luting cement irradiated with different light sources as well energy density through a ceramic sample. Three light-curing unit (LCUs) were tested: tungsten halogen light (HAL), light-emitting diode (LED) and xenon plasma-arc (PAC) lamp. Disc-shaped specimens were fabricated from a resin-based cement (Enforce). Three energy doses were used by modifying the irradiance (I) of each LCU and the irradiation time (T): $24 \mathrm{Jcm}^{-2}$ (I/2x2T), $24 \mathrm{Jcm}^{-2}$ (IxT) and $48 \mathrm{Jcm}^{-2}$ (Ix2T). Energy doses were applied through a 2.0-mm-thick ceramic sample (Duceram Plus). Three groups underwent direct irradiation over the resin cement with the different LCUs and a chemically-activated group served as a control. Thirteen groups were tested $(n=10)$. Knoop hardness number $(\mathrm{KHN})$ means were obtained from cross-sectional areas. Two-way ANOVA and the Holm-Sidak method were used for statistical comparisons

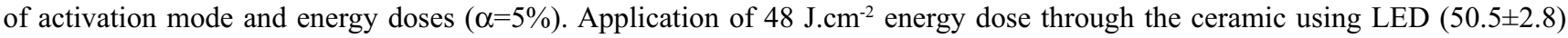
and HAL $(50.9 \pm 3.7)$ produced significantly higher KHN means $(\mathrm{p}<0.05)$ than the control $(44.7 \pm 3.8)$. LED showed statistically similar performance to HAL. Only HAL showed a relationship between the increase of LCU energy dose and hardness increase.
\end{abstract}

Key words: Hardness test. Resin cements. Ceramics. Dental materials.

\section{INTRODUCTION}

Several factors can influence the degree of polymerization of resin cements, namely, porcelain shade and thickness ${ }^{4}$, light-curing unit (LCU) and curing time ${ }^{12}$. Dual-cured resin luting agents are usually chosen based on the best combination of mechanical and physical properties when the efficacy of light activation is doubtful. Light activation of dual-cured resin-based materials is necessary to maximize strength and rigidity of composites ${ }^{2}$. Also, maximum bond strength of dual-cured cements is achieved only when light activation is properly done $e^{3,8,17}$. It is important to understand the light activation process of dualcured resin cements because of the differences existing between light activation methods ${ }^{20}$, including energy density, spectral distribution ${ }^{16}$ of the light emitted by the $\mathrm{LCU}$ and the polymerization process itself ${ }^{18}$.

It has been advocated that low irradiation output of LCUs may be compensated by increasing the irradiation time, without affecting the conversion degree for composites, in such a way that different LCUs can have the same energy density $\left(\left[\mathrm{mW} / \mathrm{cm}^{2}\right] \mathrm{x} T\right)$. The concept of energy density is based on the theory that polymerization of lightactivated composite resins depends on the total energy delivered to it ${ }^{7,14,21}$.

This study tested the following null hypotheses: (1) different LCUs (HAL, LED and PAC) have similar effects on the microhardness of a dual-cured resin cement when equivalent energy dose is applied, and (2) Different energy doses do not significantly reduce Knoop hardness.

\section{MATERIAL AND METHODS}

Feldspathic ceramic material (Duceram Plus; Ducera Dental GmbH\&Co.KG, Rosbach, Germany; VITA shade dentin A3) was condensed into a metallic mold to produce a cylindrical specimen that was fired in ceramic furnace. One 
disc-shaped specimen ( $2.0 \mathrm{~mm}$ thick $\times 1.0 \mathrm{~mm}$ in diameter $)$ was obtained and submitted to finishing and glaze firing.

A resin cement (Enforce with fluoride; Dentsply, Ind. e Com. Ltda, Petrópolis, RJ, Brazil) was mixed according to the manufacturer's instructions and in compliance with ISO 4049 standard $^{10}$, and inserted into a black painted nylon mold with a central hole $(5.0 \mathrm{~mm}$ in diameter $\mathrm{x} 1.0 \mathrm{~mm}$ thick $)$. The chemically activated group (control, $\mathrm{n}=10$ ) was mixed in a dark room with a red light filter to avoid light initiator sensitization. When the dual activation was used, the resin cement was light-irradiated by two modes: direct lightactivation (DLa) or irradiation through ceramic (LtC). In this latter mode, a ceramic disc was interposed between the tip of LCU and the polyester film ( $\pm 25-\mu \mathrm{m}$ thick) placed onto the resin cement and irradiation was performed using one of the 3 energy doses (Table 1)

Three LCUs were used: HAL-tungsten halogen (XL 2500; 3M/ESPE, St Paul, MN, USA; mean irradiance of $589 \mathrm{~mW} /$ $\mathrm{cm}^{2}$ ); LED-light-emitting diode (Ultrablue Is, D.M.C. Equipamentos LTDA, São Carlos, SP, Brazil; mean irradiance of $614 \mathrm{~mW} / \mathrm{cm}^{2}$ ); and PAC-xenon plasma arc (Apollo 95E, DMD - Medical Diagnostic Systems, Westlake Village, CA, USA; mean irradiance of $1,656 \mathrm{~mW} / \mathrm{cm}^{2}$ ). The LCUs were connected to a voltage stabilizer and supported by an apparatus to allow positioning the tip of LCU at $90^{\circ}$ to material surface. A hand-held radiometer (Hilux, Dental Curing Light Meter, Benbionglu Dental Inc., Turkey) was used to check irradiance of the three LCUs. Readings were made after 10 activation sequences for each device. Times were adjusted according to the irradiance of each LCU to reach the desired energy doses, according to the equation:

$D=\frac{P}{A} \quad x T=\frac{m W}{\mathrm{~cm}^{2}} \quad x s=\frac{\mathrm{mJ}}{\mathrm{cm}^{2}}$

Where: "P" is the potency of LCU (mW), " $\mathrm{A}$ " is the area of the output light guide for the LCU $\left(\mathrm{cm}^{2}\right)$ and " $\mathrm{T}$ " is the irradiation time (s). The irradiance data given for each handheld radiometer $\left(\mathrm{mW} / \mathrm{cm}^{2}\right)$ were used for $\mathrm{P} / \mathrm{A}$. " $\mathrm{D}$ " is the resulting energy dose in $\mathrm{mJ} / \mathrm{cm}^{2}\left(\mathrm{~J}_{\mathrm{cm}} \mathrm{cm}^{-2}\right)$.

Three energy doses were applied through the ceramic sample (Table 1), based on an equivalence condition to the $600 \mathrm{~mW} / \mathrm{cm}^{2}$ irradiance obtained with halogen lamps for 40 $\mathrm{s}$. In order to decrease the irradiance to approximately half of the original values, the tips of the LCU light guides were kept at a distance of $7.7 \mathrm{~mm}$ (HAL), $4.8 \mathrm{~mm}$ (LED) and 4.75 $\mathrm{mm}$ (PAC) from material surface.

For each LCU, one group was prepared with DLa (no interposed ceramic) for the hardness test using optimal light activation conditions. The irradiation time was set as specified in the manufacturers' instructions $(\mathrm{HAL}=40 \mathrm{~s}$, $\mathrm{LED}=40 \mathrm{~s}$ and $\mathrm{PAC}=3 \mathrm{~s}$ ). One group was prepared in a lightproof environment to obtain the chemically-polymerized hardness profile. Combination of LCUs and test conditions resulted in 13 groups $(\mathrm{n}=10)$ (Table 2).

TABLE 1- Design of study

Light-activation without ceramic Light-activation (dual-cured mode) through 2.0-mm-thick ceramic

\begin{tabular}{|c|c|c|c|c|}
\hline (Cact) & (DLa) & $24 \mathrm{~J}^{-\mathrm{cm}^{-2}(\mathrm{I} / 2 \times 2 \mathrm{~T})}$ & 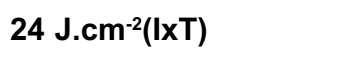 & $48{\mathrm{~J} . \mathrm{cm}^{-2}}^{-(\mathrm{Ix} 2 \mathrm{~T})}$ \\
\hline & $I=589 \mathrm{~mW} / \mathrm{cm}^{2}$ & $I=300 \mathrm{~mW} / \mathrm{cm}^{2}$ & $I=589 \mathrm{~mW} / \mathrm{cm}^{2}$ & $I=589 \mathrm{~mW} / \mathrm{cm}^{2}$ \\
\hline & $T=40 \mathrm{~s}$ & $T=82 \mathrm{~s}$ & $T=40 \mathrm{~s}$ & $T=82 \mathrm{~s}$ \\
\hline HAL & $S=1$ & $S=1$ & $S=1$ & $S=1$ \\
\hline & $D=0 \mathrm{~mm}$ & $D=7.7 \mathrm{~mm}+$ ceramic & $D=$ contact with ceramic & $D=$ contact with ceramic \\
\hline & $I=613.8 \mathrm{~mW} / \mathrm{cm}^{2}$ & $I=300 \mathrm{~mW} / \mathrm{cm}^{2}$ & $I=613,8 \mathrm{~mW} / \mathrm{cm}^{2}$ & $I=613.8 \mathrm{~mW} / \mathrm{cm}^{2}$ \\
\hline & $T=40 \mathrm{~s}$ & $T=78 \mathrm{~s}$ & $T=40 \mathrm{~s}$ & $T=78 \mathrm{~s}$ \\
\hline ED & $S=1$ & $S=1$ & $S=1$ & $S=2$ \\
\hline & $D=0 \mathrm{~mm}$ & $D=4.8 \mathrm{~mm}+$ ceramic & $D=$ contact with ceramic & $D=$ contact with ceramic \\
\hline & $I=1,653 \mathrm{~mW} / \mathrm{cm}^{2}$ & $I=825 \mathrm{~mW} / \mathrm{cm}^{2}$ & $I=1653 \mathrm{~mW} / \mathrm{cm}^{2}$ & $I=1,653 \mathrm{~mW} / \mathrm{cm}^{2}$ \\
\hline & $T=3 \mathrm{~s}$ & $T=29 \mathrm{~s}$ & $T=15 \mathrm{~s}$ & $T=29 \mathrm{~s}$ \\
\hline & $S=1$ & $S^{*}=9+1(2 s)$ & $S^{*}=5$ & $S^{*}=9+1(2 s)$ \\
\hline & $D=0 \mathrm{~mm}$ & $D=4.5+$ ceramic & $D=$ contact with ceramic & $D=$ contact with ceramic \\
\hline
\end{tabular}

$\mathrm{LCU}=$ light-curing unit; $\mathrm{HAL}=$ tungsten halogen light; $\mathrm{LED}=$ light-emitting diode and $\mathrm{PAC}=$ xenon plasma-arc; Cact= chemical activation only; $\mathrm{DLa}=$ direct light-activation; I= Irradiance or energy density of the LCU, used for specific energy dose. I/2= approximately half full potential irradiance of the LCU; T= Irradiation time; $S=$ Turn-on sequences needed to achieve irradiation time. $S^{*}=$ for PAC, there was a 3-s delay among "turn-on" sequences. $D=$ Distances between tip of light guide and resin cement surface. 
Specimens were stored in a culture oven under dry storage and dark conditions at $37^{\circ} \mathrm{C}$ for approximately $24 \mathrm{~h}$. After storage, specimens were fixed in a previously prepared acrylic mold, using sticky wax to improve fixation and fill gaps, avoiding misfit. Resin cement discs were sectioned longitudinally and cement surface was finished and polished with abrasive papers in a decreasing sequence of abrasiveness (\#180, \#320, \#400,\#600 and \#1200 grit).

A universal indenter tester (HMV-2, Shimadzu, Tokyo, Japan) was set at the automatic mode with $50 \mathrm{~g}$ of force for $15 \mathrm{~s}$. Indentation measurements were made manually at $40 \mathrm{X}$ magnification across the section of the resin cement specimens. Knoop hardness number $\left(\mathrm{KHN}, \mathrm{kg} / \mathrm{mm}^{2}\right)$ was calculated based on the indentation measurement obtained by a single operator. Three indentations were made on each specimen at $1-\mathrm{mm}$ distance from each other, at $100-\mu \mathrm{m}$ depth from the irradiated surface. The arithmetic mean was calculated for each specimen.

Overall changes in $\mathrm{KHN}$ at $100-\mu \mathrm{m}$ depth were evaluated by two-way ANOVA and Holm-Sidak method as a post-hoc test. One-way ANOVA and Holm-Sidak test were performed for comparison of all groups versus chemical-activation mode (control). All tests were performed at the 0.05 level of significance.

\section{RESULTS}

KHN means at $100-\mu \mathrm{m}$ depth showed a statistically significant interaction between LCUs and activation methods $(p=0.02)$. When direct light activation was performed, HAL showed significantly higher KHN means than LED and PAC $(\mathrm{p}<0.05)$. No significant differences were found between LED and PAC (Table 2).

For Ix2T and I/2x2T energy doses, LED and HAL showed significantly higher KHN means than $\mathrm{PAC}(\mathrm{p}<0.05)$, but HAL and LED groups were statistically similar. KHN means obtained with LED were similar to those obtained with HAL

TABLE 2- KHN means at $100-\mu \mathrm{m}$ depth for each light-curing unit $(n=10)$ according to the different activation modes

Light irradiation mode

LCU

Energy doses through 2.0-mm-thick ceramic (LtC)

DLa

$\mathrm{HAL}$

$24{\mathrm{~J} . \mathrm{cm}^{-2}}(\mathrm{IXT})$

$24 \mathrm{~J} . \mathrm{cm}^{-2}(\mathrm{I} / 2 \times 2 \mathrm{~T})$

LED

$47.2(4.4) \mathrm{b}, \mathrm{B}$

*50.9 (3.7)a,A

45.5 (1.1)a,B

47.0 (2.3)ab,B

PAC *47.7 (2.1)b,A

*50.5 (2.8)a,A

$47.2(4.2) \mathrm{a}, \mathrm{B}$

*48.7 (3.5)a, $\mathrm{AB}$

$46.2(2.9) b, A$

$46.6(2.3) \mathrm{a}, \mathrm{A}$

$45.5(2.2) \mathrm{b}, \mathrm{A}$

$\mathrm{LCU}=$ light-curing unit; $\mathrm{HAL}=$ tungsten halogen light; $\mathrm{LED}=$ light-emitting diode and $\mathrm{PAC}=$ xenon plasma-arc; $\mathrm{DLa}=$ direct light-activation; Different uppercase letters in rows represent statistically significant differences $(p<0.05)$ among light irradiation modes for each LCU. Different lowercase letters in columns represent statistically significant differences $(p<0.05)$ among the LCUs for each light activation mode. Standard deviations are given in parenthesis for each mean. $\left({ }^{*}\right)$ means are significantly higher than control (chemical activation only) [44.7 (3.8)].

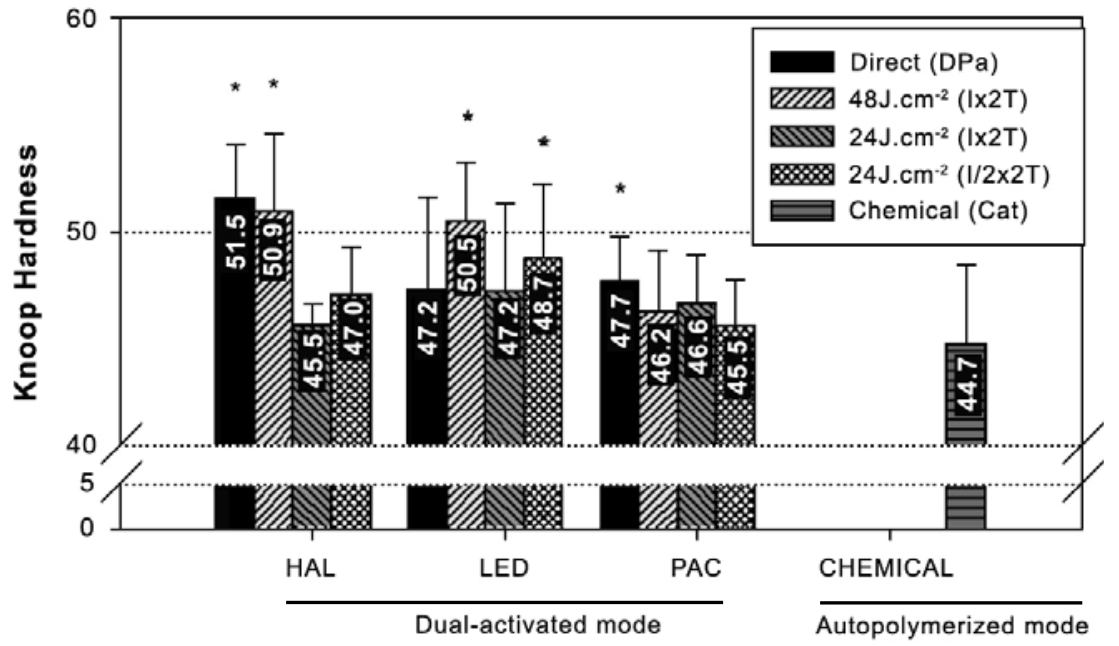

\section{Activation Mode}

FIGURE 1- KHN means at 100- $\mu \mathrm{m}$ depth for each light-curing unit $(n=10)$ according to the different activation modes. Asterisk represents means that are significantly higher than the control (chemical activation only) 
for all energy doses (LtC mode). HAL setting at $48 \mathrm{Jcm}^{-2}$ showed significantly higher KHN means than the other modes of indirect irradiation $(\mathrm{p}<0.05)$. Differences were not found among the activation modes with PAC.

When the experimental groups were compared to the chemically-activated control group, DLa with HAL and PAC led to significantly higher KHN means $(\mathrm{p}<0.05)$. PAC showed similar hardness to that of the control group for other energy doses through ceramic. Only LED set at I/2x2T showed significantly higher KHN means $(\mathrm{p}<0.05)$ than the control (Figure 1).

\section{DISCUSSION}

The first null hypothesis was rejected because hardness was significantly affected by the type of LCU, depending on the light-activation modes. The results showed a statistically significant interaction between LCU and activation method. Thus, in addition to the energy dose $\mathrm{e}^{7,21}$ the efficiency of the irradiation mode was dependent on the type of LCU. The different output wavelengths, spectral irradiance, light power, as well as differences in the efficiency of the optical delivery system, including the light-guide tips, can affect hardness ${ }^{7,14}$.

HAL and PAC had similar effects on hardness when used in the Ix2T mode. However, when these LCU were used in the DLa mode, HAL performed better than PAC. In addition, the HAL $48 \mathrm{Jcm}^{-2}$ dose was statistically superior to the control and to other energy doses, while similar to the DLa mode. Thus, when irradiation was performed with HAL, the highest hardness values were obtained with Ltc mode when the highest energy dose was applied. Based on this evidence, the second null hypothesis was rejected. The hardness was dependent on the energy dose used when the halogen LCU was employed. In general, energy dose is well correlated with a polymerization profile for each composite. ${ }^{23}$ However, when composites and LCUs are compared, the energy dose concept should be treated with caution ${ }^{4}$.

The LED LCU used in this study provided an adequate hardness with energy doses of Ix $2 \mathrm{~T}$ and I/2x2T, which were, respectively, superior and similar to DLa (no interposed ceramic) and higher than the control. Although the energy dose of Ix2T $\left(48 \mathrm{Jcm}^{-2}\right)$ was twice as that of $\mathrm{I} / 2 \times 2 \mathrm{~T}\left(24 \mathrm{Jcm}^{-2}\right)$, KHN means were similar. This similarity can be due to the exposure time, almost 3 times greater than the irradiation time for PAC under the same conditions. It may be of particular importance in some clinical conditions, such as light curing in proximal areas of inlays, where the placement of the LCU light-guide at a certain distance may be a hindrance to irradiation.

The LED dose of Ix2T showed significantly higher KHN means than DLa. In a previous study ${ }^{15}$, LED lights provided greater curing depths with A3 shade, while halogen lights had greater curing depths with $\mathrm{C} 4$ shade. Since the ceramic used was shade A3, perhaps this fact contributed to the observed differences. Certainly, one of the most important factors to consider is that the final irradiation time was twice as that of DLa.

The emission of wavelengths (around $469 \mathrm{~nm}$ ) in specific excitation peak is related with composite scraping depth that is an ISO measuring method ${ }^{14}$. According to other studies, LEDs have a spectral radiance close to the camphorquinone excitation peak. Furthermore, as shown by Hofmann ${ }^{9}$, the degree of polymerization with a shorter wavelength-specific band for LCU can be compensated with higher exposure times. Probably for these reasons, irradiation for approximately $80 \mathrm{~s}$ with LED showed good hardness values.

Halogen light, in direct use, can better fulfill the requirements as a photoinitiator of resin cement due to its broad spectral irradiance. Manufacturers should provide a graph indicating the minimum acceptable exposure for each product for specified curing lamps ${ }^{15}$, since some photoinitiators used have specific irradiance requirements. ${ }^{5}$ The understanding of light attenuation effect of ceramics is also important and should be considered for the choice of cement and activation mode.

It has been found that the increase of the exposure time may overcome the effect of less specific wavelength for composite resin ${ }^{11}$. If some change to the useful wavelength occurred due to the ceramic, then the change could be compensated with longer exposures times used for HAL and LED LCUs. Shorter irradiation times have been advocated for PAC LCUs ${ }^{5}$, but these reduced light-activation time and interrupted activations sequences could change the kinetics of polymerization with PAC.

Only DLa with 3-s irradiation provided higher KHN means at 100 ìm depth than that of the control group. Although PAC devices used in direct activation have shown satisfactory results in light-activation of thin composite layers $^{3,17}$, PAC techniques require a significant increase in the irradiation time when applied to indirect polymerization ${ }^{19}$. The delay between light emission, features inherent to light, such as spectrum, energy absorbance and attenuation, and features inherent to the ceramic may have negatively affected the polymerization kinetics.

Despite the five situations that differ from the chemicalactivation mode, doses with longer times (I/2x2T and Ix2T) for HAL and LED showed advantages compared to other conditions (except for LED I/2x2T). In those situations, when KHN means were similar to the control, the results should be carefully interpreted based on microhardness methodology. Some resin cements have shown low hardness at first time post-polymerization with a decrease of strength against immediate loads ${ }^{6}$. It has been reported that postpolymerization storage conditions influence composite microhardness ${ }^{8}$. Light-activation is always desired for improvement of mechanical properties of resin cements immediately after cementation ${ }^{2,12}$. Like hardness ${ }^{22}$, adhesion can be significantly improved ${ }^{1}$ when an effective LCU is used since bond strength is dependent on the irradiance level applied through ceramic ${ }^{13}$. Additionally the use of LCUs with high output irradiances is preferable instead of increasing the exposure time to compensate low output 
irradiances.

\section{CONCLUSIONS}

Within the limitations of this study, it may be concluded that: 1. HAL and LED LCUs had similar performance, according to KHN means of resin cement when irradiation through ceramic was used; 2 . The chemical-activation mode was similar to the light/chemical-activation mode of the several protocols proposed in the study, representing a satisfactory chemical reaction profile of the tested resin cement; 3. Only HAL showed a relationship between hardness increase and increase of energy dose; 4. PAC showed similar or sometimes lower hardness than that obtained with the other LCUs.

\section{REFERENCES}

1- Aksornmuang J, Nakajima M, Foxton RM, Tagami J. Mechanica properties and bond strength of dual-cure resin composites to root canal dentin. Dent Mater. 2007;23:226-34.

2- Attar N, Tam LE, McComb D. Mechanical and physical properties of contemporary dental luting agents. J Prosthet Dent. 2003;89:12734

3- Braga RR, Ballester RY, Carrilho MR. Pilot study on the early shear strength of porcelain-dentin bonding using dual-cure cements. J Prosthet Dent. 1999;81:285-9.

4- Breeding LC, Dixon DL, Caughman WF. The curing potential of light-activated composite resin luting agents. J Prosthet Dent. $1991 ; 65: 512-8$

5- Dietschi D, Marret N, Krejci I. Comparative efficiency of plasma and halogen light sources on composite micro-hardness in different curing conditions. Dent Mater. 2003;19:493-500.

6- El-Mowafy OM, Rubo MH, el-Badrawy WA. Hardening of new resin cements cured through a ceramic inlay. Oper Dent. 1999;24:3844.

7- Halvorson RH, Erickson RL, Davidson CL. Energy dependent polymerization of resin-based composite. Dent Mater. 2002;18:4639.

8- Hasegawa EA, Boyer DB, Chan DC. Hardening of dual-cured cements under composite resin inlays. J Prosthet Dent. 1991;66:187-92.

9- Hofmann N, Hugo B, Schubert K, Klaiber B. Comparison between a plasma arc light source and conventional halogen curing units regarding flexural strength, modulus, and hardness of photoactivated resin composites. Clin Oral Investig. 2000;4:140-7.

10 - International Organization for Standardization. Dentistry polymer-based filling, restorative and luting materials. ISO 4049:2000 Available at: http://www.iso.ch/iso/en/prods-services/ISOstore/ store.html. Accessed October 28, 2005.

11 - Jung H, Friedl KH, Hiller KA, Haller A, Schmalz G. Curing efficiency of different polymerization methods through ceramic restorations. Clin Oral Investig. 2001;5:156-61.

12 - Linden JJ, Swift EJ Jr, Boyer DB, Davis BK. Photo-activation of resin cements through porcelain veneers. J Dent Res. 1991;70:154-
13 - Moraes RR, Correr-Sobrinho L, Sinhoreti MA, Puppin-Rontani RM, Ogliari FA, Piva E. Light-activation of resin cement through ceramic: relationship between irradiance intensity and bond strength to dentin. J Biomed Mater Res B Appl Biomater. 2008;85(1):160-5

14- Musanje L, Darvell BW. Polymerization of resin composite restorative materials: exposure reciprocity. Dent Mater. 2003;19:53141

15- Nomoto R. Effect of light wavelength on polymerization of light-cured resins. Dent Mater J. 1997;16:60-73.

16- Nomoto R, McCabe JF, Hirano S. Comparison of halogen, plasma and LED curing units. Oper Dent. 2004;29:287-94.

17- Peters AD, Meiers JC. Effect of polymerization mode of a dualcured resin cement on time-dependent shear bond strength to porcelain. Am J Dent. 1996;9:264-8.

18 - Pradhan RD, Melikechi N, Eichmiller F. The effect of irradiation wavelength bandwidth and spot size on the scraping depth and temperature rise in composite exposed to an argon laser or a conventional quartz-tungsten-halogen source. Dent Mater. 2002;18:221-6.

19- Quance SC, Shortall AC, Harrington E, Lumley PJ. Effect of exposure intensity and post-cure temperature storage on hardness of contemporary photo-activated composites. J Dent. 2001;29:55360 .

20- Rahiotis C, Kakaboura A, Loukidis M, Vougiouklakis G. Curing efficiency of various types of light-curing units. Eur J Oral Sci. 2004;112:89-94.

21 - Rueggeberg F. Contemporary issues in photocuring. Compend Contin Educ Dent. Suppl 1999:S4-15.

22- Tango RN, Sinhoreti MA, Correr AB, Correr-Sobrinho L, Henriques GE. Effect of light-curing method and cement activation mode on resin cement Knoop hardness. J Prosthodont. 2007;16:4804.

23 - Tanoue N, Matsumura H, Atsuta M. Curing depth of a composite veneering material polymerized with seven different laboratory photo-curing units. J Oral Rehabil. 1998;25:199-203. 